\title{
Cultural Divergence in Website Interaction Spanish vs. English
}

\author{
Nicholas Iuliucci and Ania Rodriguez \\ Key Lime Interactive, 3901 NW 79 Ave, Ste 10733166 Doral, Florida USA \\ $\{$ Nick, Ania\}@keylimeinteractive.com
}

\begin{abstract}
Our perception of the world around us is based on our knowledge and experiences. Web design has used this concept to improve websites by matching expectations derived from the knowledge and experience to design concepts. Understanding the role culture plays in perception of websites needs to be better understood. This paper uses eye-tracking gaze patterns (ETMAP) in conjunction with a cultural identification survey (ARSMA-II) to explore divergences between American and Latino-Americans. Our results suggest a relationship between sequential reading and scanning behaviors with acculturation scores. While these results demonstrate that the methodology has potential, the findings need to be confirmed in future studies.
\end{abstract}

Keywords: Eye-tracking, Usability, Gaze Patterns, Spanish, Acculturation, Culture, ARSMA-II, ETMAP.

\section{$1 \quad$ Localization of Website Design}

The usability of a webpage is based on the degree to which it meets a user's expectations. Many US-based companies have entered various foreign markets with their existing business models and websites, designed for users, with limited success. In 2002, eBay was forced to withdrawal from the Japanese market due to its faulty assumption that Japanese market mirrored the American one. What E-Bay and other companies quickly realized is that when entering foreign markets the website needs to be localized to match cultural expectations. Research reinforces the call for customization of media to fit the cultural expectations of foreign target markets (Ahmed 2008).

The idea that culture impacts perception has been discussed and studied as early as the 1900's (Rivers, Sapir and Whorf) with supporting research in 1966 (Segal), 1978 (Detweiler), and 1990 (Deregowski), creating a strong foundation for research into understanding the relationship. [The basis for the argument is derived from the fact that how we view the world around us and interact with elements within the environment is a product of our experiences and knowledge (Matthew Hiller, 2003).] Hiller (2003) concluded that three main elements are important to creating a multilingual website: language, cultural context and usability. These three elements seem distinct, but they are strongly interdependent. Language is the tool that allows for communication between members of that group. Embedded into language is a set of 
gender expectations and interaction rules. When a website or other media is applied to a different market or region and the language is only modified at face value, it lacks the supporting structure that refines and clarifies the intended message. Together language and cultural context provide the structure for how a website should be refined to deliver a clear and distinct message, thereby creating an interaction that is easy to understand and follows logically with the user's expectation. The matching of website structure and content to a user's expectation is the basic goal of usability.

\subsection{Culture and Usability}

Cultural research is broken into two main focuses: objective and subjective culture. Objective includes socially constructed labels or elements, while subjective is based on internalization of cultural elements. Subjective culture has two layers: anthropological and cognitive processing that comprise the majority of research. Investigations from multiple angles have been conducted ranging from cultural values (Hofstede, 1991), cognitive processing preference (Punchoojit \& Chintakovid, 2012) and element preference for web design (Smith, Barder \& Badre, 1998).

Based on a massive global survey, Hofstede (1991) developed five cultural dimensions: Power Distance, Individualism, Masculinity vs Femininity and Uncertainty Avoidance. For a given country, each dimension has a numerical value representing the level of adherence or relationship to the dimension. Zahed et al (2001) developed a conceptual framework that presented specific propositions on how various cultural factors may impact the effectiveness of a website based on Hofstede's cultural dimensions. Hofstede's focus on the values of each country extends our understanding of culture at an anthropological layer.

Cultural differences have been examined at the cognitive processing layer of subjective culture. Punchoojit \& Chintakovid (2012) examine culture via a processing lens, suggesting that for example: Americans have analytical approach to information, while Easterners such as Chinese or Japanese assimilate information holistically. Matching cognitive preference with related design elements improves user experience, linking another cultural layer to usability (Nisbett, 2008). While structural layout of web design has been influenced by research on both subjective layers of culture, individual elements in the design are linked to cultural preferences.

It has been established that culture influences preference of design elements for websites (Cyr \& Trevor-Smith, 2004). Element preferences for a given culture manifest in aspects such as color, grouping, fonts, shapes and architecture are considered cultural markers (Barber \& Badre, 1998). Barber and Badre (1998) suggest that these differences of element preference by culture are the product of cultural norms, belief systems and several other factors.

\subsection{Eye-Tracking and Culture}

Dong and Lee (2008) conducted eye tracking research which has indicated that Easterners (Korean \& Chinese) utilize a circular scan pattern more often than Westerners (Americans) when viewing identical sites with only language being 
localized. The research utilized a technique called Eye Tracking Map Analysis Procedure (ETMAP). Using the procedure, shown in Figure 1, a higher rate of circular gaze patterns were observed on average for Easterners compared to Westerners, who on average exhibited more linear gaze patterns (Dong \& Lee, 2008). The results were cited as evidence supporting that matching cultural cognitive preference with related design elements improves user experience (Nisbett, 2008). Aforementioned research focuses on the cognitive processing layer of subjective cultural and its influence on web design (Punchoojit \& Chintakovid, 2012). Dong \& Lee (2003) argue that differences in movement patterns may occur as a result of cultural deviations between groups. The results rely on the assumption that the 9 individuals per group (American vs. Asian) had internalized and primarily identified as that group at an individual level. This is in contrast to the idea that an individual can internalize cultural influences to different degrees. Individuals who are exposed in equal amounts can display characteristics of both cultural traits. Individuals internalize organizational and structural features of a given culture to varying degrees. Accounting for this aspect could provide clarity when analyzing results.

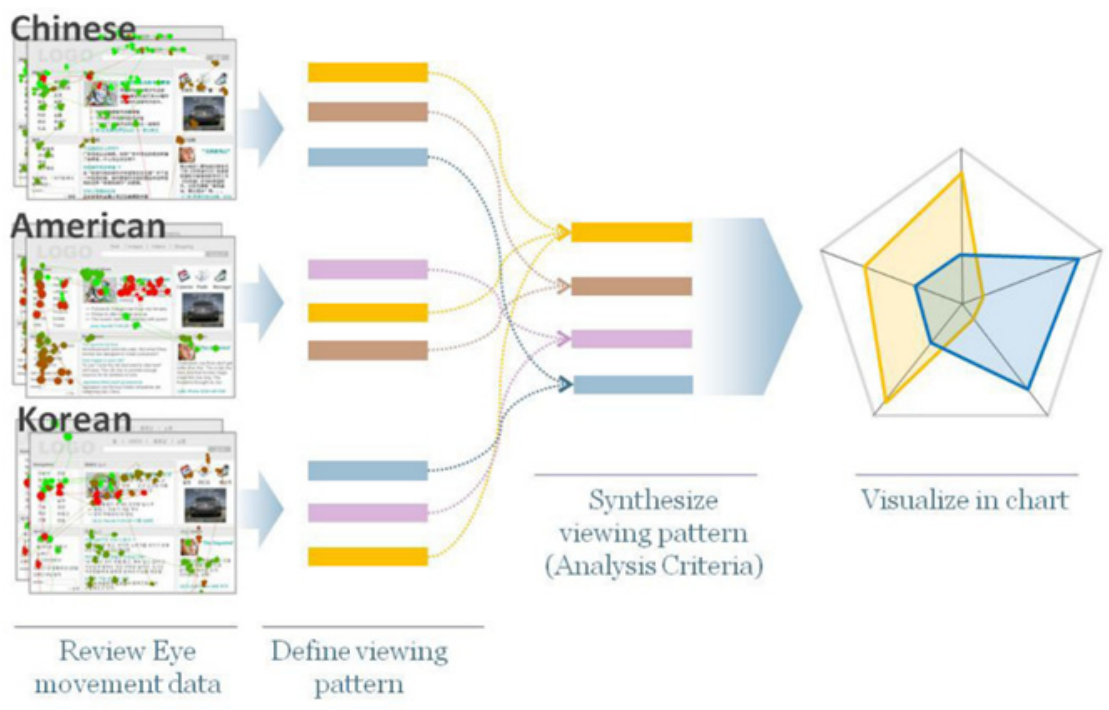

Fig. 1. Eye Tracking Mapping Analysis Procedure (Dong \& Lee, 2003)

\subsection{Acculturation}

The term "acculturation" is defined as "the cultural modification of an individual, group, or people by adapting to or borrowing traits from another culture" (Webster Dictionary). At an individual level, this means exposure to another culture or socially constructed group. The knowledge and experiences gained from the exposure influence their perception of the outside world and their internal identities. The degree of this influence is dependent on the length of exposure, willingness and timing or age of interactions for a given culture. For example using the figure 2 (Marino, 2011), 
"John" grew up in Guatemala moving to the US at a young age. As John is no longer living in Guatemala, his level of exposure to the culture will be derived from his family interactions, such as food, customs, values and language. Outside his family, interactions with institutions (schools, government and social) will be primarily based in American culture. John mediates the influence of these two external forces based on the degree to which aspects from each culture become internalized into his identity and is expressed by how John sees himself.

Individual cultural identification is assessed mainly through survey methods (Marino, 2011). Out of the various surveys developed, the Acculturation Rate Scale for Mexican Americans- II (ARSMA II) stands out from the rest and is an accepted tool by the American Psychological Association (Cellular et al, 2009). The ARSMA II consists of 48 Likert scale questions with five subscales: Anglo Orientation Subscale (AOS), Mexican Orientation Subscale (MOS), ANGMAR, MEXMAR and MAMAR. The original two scales AOS and MOS, developed over 30 years ago, can be combined to produce an acculturation rating on a scale that ranges from -3 to 3 . The acculturation rating that results from the ARSMA-II is designed to gauge the psychological and behavior patterns that signify preference between two cultures.

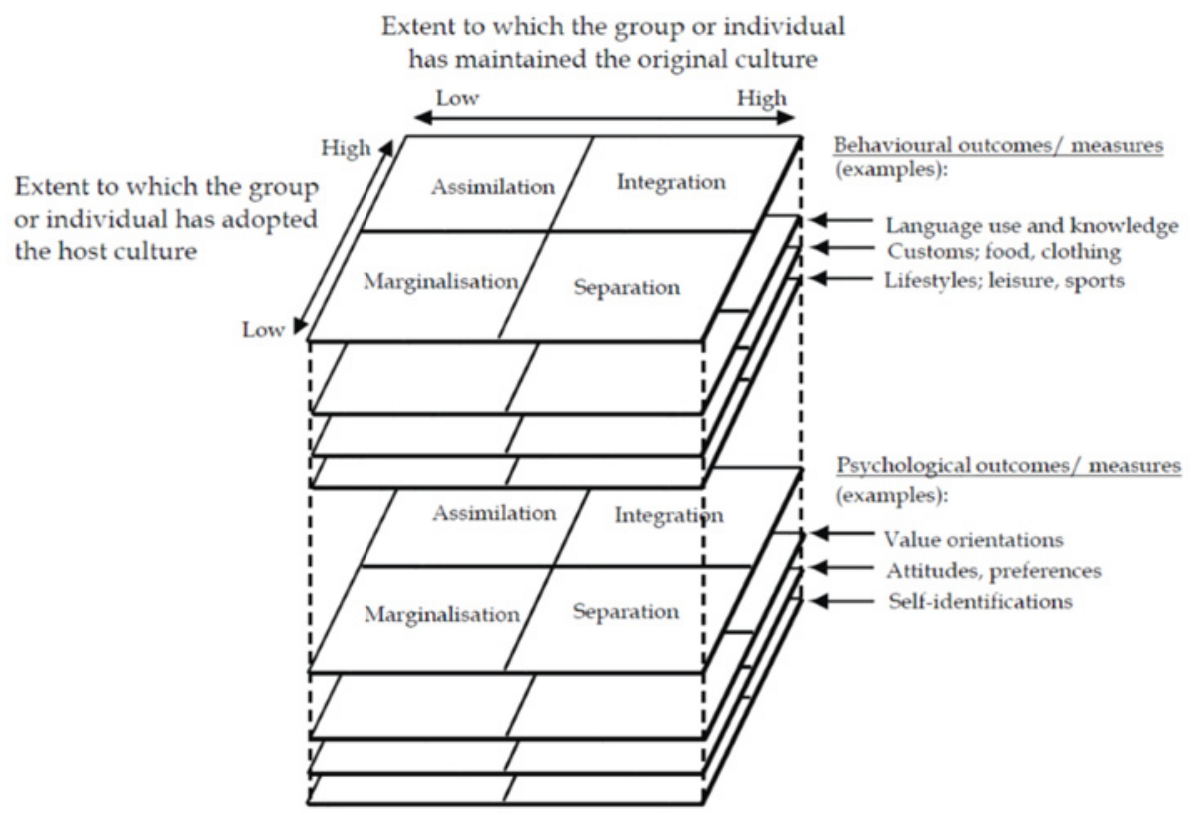

Fig. 2. Domains of Acculturation. Cultural is comprised of both behavioral and psychological outcomes. (Marino, 2011)

\subsection{Hypothesis}

The ARSMA II represents a method to reliably quantify the individual level acculturation. Eye-tracking provides a modality to investigate cultural preferences for 
design elements and gaze pattern. We hypothesize that ARSMA-II scores will be correlated with gaze patterns that have been modified from Dong \& Lee's criteria so they can be used to assess individuals.

\section{Methods}

Thirty participants were recruited for this study with an equal gender representation (15 males and 15 females). The average age is 20.8 years old $(\mathrm{SD}=2.93)$ and range in education from 1st college students to graduate students, but a majority (15) are 1-2 year students. All participants had either normal or minimally corrected vision. The study was conducted on 2 sites, Rochester New York and Miami Florida, with half the total number coming from each. Half of the participants are bilingual (English and Spanish), while the other half consist of English speaking only participants with limited exposure to Latino culture. Their degree of cultural exposure to Latin and American cultural was identified through the use of the ARSMA-II. Additional questions to gauge their interest in site topic were included along with the demographic questions inherent in the ARSMA-II. The eye-tracking was conducted using a SensoMotoric Instruments (SMI) RED250 at the Rochester testing site and a SMI RED-M for Miami testing. Each participant was shown 7 websites and allowed to free roam a static image of the site for 30 seconds. The test websites consisted of three United States marketed websites (Consumer Financial, BestBuy and Coca-Cola) and four Latino marketed versions with Coca-Cola having 2 Spanish sites (Venezuela and Chile targeted sites). The websites were displayed on a $1280 \times 1024$ monitor at the Rochester location and a 15.6" laptop for Miami testing.

Once each participant had agreed to participate in the study and signed the consent form, they were seated in front of the eye-tracking monitor. Once sitting comfortably the participant was asked to remain in the posture without touching their face or hair. A calibration test was ran, followed by a four point validation. The $\mathrm{X}$ and $\mathrm{Y}$ variation was only accepted if a .5 degrees or below was achieved. The first webpage image was then displayed on the screen for 30 seconds after which it was automatically replaced by a two follow up question. These questions were displayed on to separate screens. Once the second question was answered the participant was presented with the next webpage. This process is repeated until all websites have been viewed. The order of website presentation was randomized by the eye-tracking system. After all seven sites had been viewed and follow up questions answered participants were asked to take the ARSMA-II. This was administered in a digital format using Google Forms. In total the testing took from 10-20 minutes, depending mainly on the rate of survey completion.

\section{Analysis}

To maintain continuity with Dong \& Lee (2003) research, the eye-tracking movements were analyzed using identical definitions for eye-tracking metrics. These definitions are as follows: 
- Fixation: a stabilized eye position within a threshold of dispersion of 2 degrees with a duration of 66 to 416 milliseconds.

- Saccade: A rapid eye movement between two fixations that last for 20 to 35 milliseconds (Poole \& Ball, 2005). Information is not processed during the movement.

- Scan path: A spatial arrangement of fixations and interconnecting saccades.

- Area of Interest (AOI): Area that has been defined by researchers to isolate elements within the environment using a common theme or rule.

- Gaze duration: Accumulative total of fixation dwell time in a defined area of interest.

Dong \& Lee (2008) used a grid of 9 uniform blocks with a top and bottom bar to analyze the eye-tracking data of their participants. While this approach cannot be directly applied to an interactive website, area of interests (AOI) can be applied to the websites selected for this study. An example of how the AOI will be applied is shown in Figure 2, with red boxes indicating the AOI.

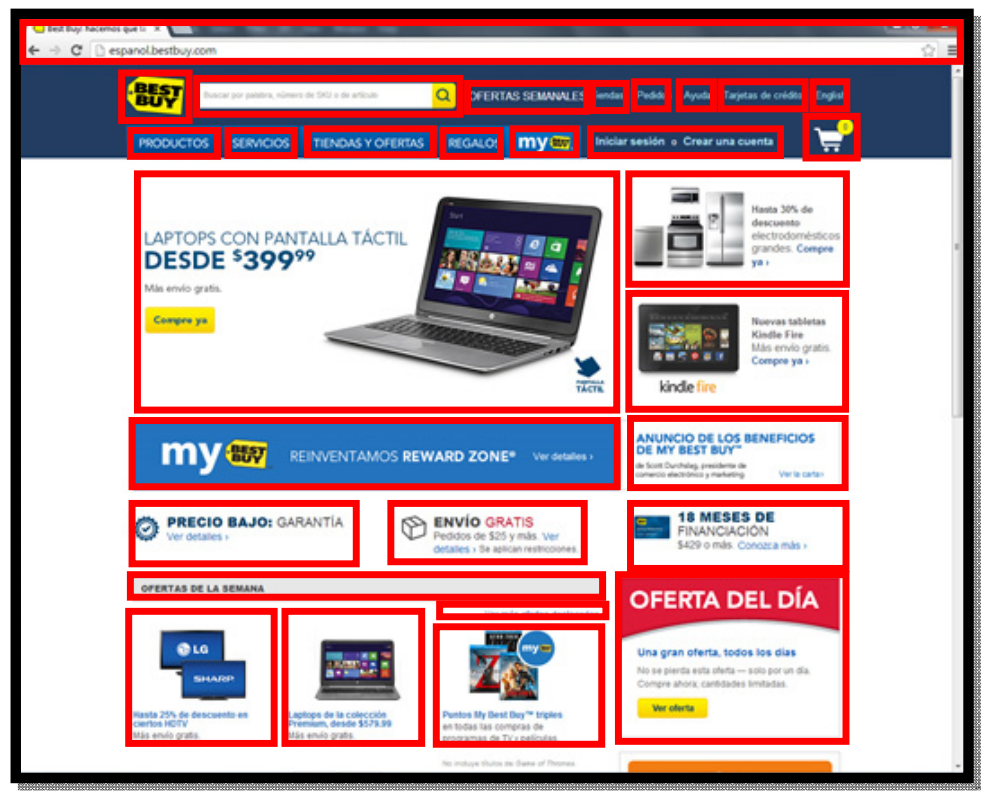

Fig. 3. Stimuli Area of Interest Application.1280x1024 still image of BestBuy Spanish version taken on October 8th, 2013. Red Boxes distinguish each AOI.

All websites will be analyzed using Dong and Lee's (2008) two sets of criteria that have been modified for both criteria presented in Tables 1 and 2 . The original method only applies to a general count of the total participants that used the gaze pattern. To apply this methodology at an individual level, the criteria for each movement has to be refined and counted for number of instants with the total 30 seconds. 
Table 1. Criteria 1. Gaze patterns redefined to account for individual pattern counts

\begin{tabular}{|l|l|l|}
\hline $\begin{array}{l}\text { Gaze } \\
\text { Pattern }\end{array}$ & $\begin{array}{l}\text { General Definition (Dong \& Lee , } \\
\text { 2003) }\end{array}$ & Redefined Definition \\
\hline $\begin{array}{l}\text { Sequential } \\
\text { Reading }\end{array}$ & $\begin{array}{l}\text { The eye moves sequentially from one } \\
\text { area to the neighboring area and } \\
\text { continuously reads contents within } \\
\text { one area. }\end{array}$ & $\begin{array}{l}\text { Reading constitutes movements to the right of } \\
\text { the initial fixation of no more than 15 letters } \\
\text { distance. 2 or more fixations must occur in same } \\
\text { AOI. }\end{array}$ \\
\hline $\begin{array}{l}\text { Circular } \\
\text { Scan }\end{array}$ & $\begin{array}{l}\text { The scan path is similar to a circle } \\
\text { being drawn on a page. }\end{array}$ & $\begin{array}{l}\text { Defined as 3 or more fixations that involve at } \\
\text { least 3 elements in circular shape. Each element } \\
\text { can have 1-2 fixations. }\end{array}$ \\
\hline $\begin{array}{l}\text { Back and } \\
\text { Forth }\end{array}$ & $\begin{array}{l}\text { The eye moves back and forth among } \\
\text { the contents; the participant visits one } \\
\text { area repeatedly within a short time. }\end{array}$ & $\begin{array}{l}\text { Defined as the movement between two AOI } \\
\text { with a repeated third visit back to the first AOI. } \\
\text { AOI 1, AOI 5, AOI 1. }\end{array}$ \\
\hline Scan Only & $\begin{array}{l}\text { The participant only scans the page, } \\
\text { without reading it in detail. This } \\
\text { pattern is shown by rapid eye } \\
\text { movements on the eye-tracking maps }\end{array}$ & $\begin{array}{l}\text { Fixations that occur in more than a single AOI, } \\
\text { ranging from 25milliseconds to 100 } \\
\text { milliseconds. 2 or more AOI's that are not } \\
\text { parallel }\end{array}$ \\
\hline $\begin{array}{l}\text { Focus on } \\
\text { Title }\end{array}$ & $\begin{array}{l}\text { The participant pays a comparatively } \\
\text { high amount of attention to the title. }\end{array}$ & $\begin{array}{l}\text { Fixation within letters of titles of elements that } \\
\text { are not incorporated into navigation. }\end{array}$ \\
\hline $\begin{array}{l}\text { Navigation } \\
\text { Reading }\end{array}$ & $\begin{array}{l}\text { The participant pays more attention to } \\
\text { the navigation bar and spends some } \\
\text { time reading the navigation items. }\end{array}$ & $\begin{array}{l}\text { Consists of } 2 \text { or more fixations with the 2nd } \\
\text { following to the right of the first and within } \\
\text { Navigation area of website }\end{array}$ \\
\hline
\end{tabular}

Table 2. Criteria 2. Gaze patterns redefined to account for individual pattern counts

\begin{tabular}{|l|l|l|}
\hline \multicolumn{2}{|c|}{ Criteria 2 } \\
\hline Pattern & General Definition & Redefined Definition \\
\hline "0" Shape & $\begin{array}{l}\text { Eye movement is similar to drawing a } \\
\text { "0" on the page }\end{array}$ & $\begin{array}{l}\text { Defined as 4 or more fixations that involve at } \\
\text { least 2 AOI's in circular shape. Each element } \\
\text { can have 1-2 fixations. }\end{array}$ \\
\hline "5" Shape & $\begin{array}{l}\text { Eye movement is similar to drawing a } \\
\text { 5" on the page }\end{array}$ & $\begin{array}{l}\text { Lateral movement left or right of initial either } \\
\text { within a single or two AOIs. Followed by a } \\
\text { vertical movement down which is then } \\
\text { proceeded by an arc movement of between 3 } \\
\text { AOIs (1-2 fixations per were accepted). }\end{array}$ \\
\hline $\begin{array}{l}\text { "N" } \\
\text { Shape }\end{array}$ & $\begin{array}{l}\text { Eyes move down one column and } \\
\text { then mover over to another column }\end{array}$ & $\begin{array}{l}\text { Lateral movement between 2 or more AOI's, } \\
\text { followed by a diagonal movement to a parallel } \\
\text { AOIs. Ending in a Lateral movement in } \\
\text { opposite direction of initial movement. (1-2 } \\
\text { fixations per AOI was accepted) }\end{array}$ \\
\hline $\begin{array}{l}\text { "Z" } \\
\text { Shape }\end{array}$ & $\begin{array}{l}\text { Eyes pass over columns first and then } \\
\text { move down the page. }\end{array}$ & $\begin{array}{l}\text { Horizontal movement between 2 or more AOI's, } \\
\text { followed by a diagonal movement to a parallel } \\
\text { AOIs. Ending in a Horizontal movement in } \\
\text { opposite direction of initial movement. (1-2 } \\
\text { fixations per AOI was accepted) }\end{array}$ \\
\hline $\begin{array}{l}\text { Eyes move diagonally across the page } \\
\text { and scan the page with random } \\
\text { jumps. }\end{array}$ & $\begin{array}{l}\text { Movement between 4 AOIs consisting of a } \\
\text { diagonal movement, followed by a lateral or } \\
\text { horizontal. The last diagonal movement must } \\
\text { bisect the original diagonal movement. }\end{array}$ \\
\hline
\end{tabular}




\section{$4 \quad$ Results}

On average, participants had lower acculturation scores in Miami ( $\mathrm{M}=.75, \mathrm{SD}=1.17)$ than in Rochester $(M=2.76, S D=1.16)$. This difference was significant $t(26)=4.56$, $\mathrm{p}<.001$, with a large effect size, $\mathrm{r}=.89$. For means of all gaze pattern criteria, please refer to tables 3 and 4 .

Regardless of testing location (MIA or ROC), acculturation was correlated with several items, varying by stimuli. The Best Buy sites demonstrated 4 correlations between acculturation and analysis criteria. From criteria 1 for the English website, acculturation was significantly correlated with Circular Scan, r=.56 and Navigation Reading, $\mathrm{r}=.41$ (both $\mathrm{p}<.05$ ). Form criteria 2, acculturation was significantly correlated with "O" shape, $\mathrm{r}=.50$ and " $\mathrm{O}$ " shape, $\mathrm{r}=.38$ (both $\mathrm{p}<.05$ ). For the Spanish website version of the Best buy site in criteria 1, acculturation was significantly correlated with scan only, $\mathrm{r}=.43, \mathrm{p}<.05$.

The Coca Cola sites demonstrated 5 correlations between acculturation and analysis criteria. From criteria 1 for the English website, acculturation was significantly correlated with Sequential Reading, r=.34, p=.07 and Back \& Forth, r= $.44, \mathrm{p}<.05$. From criteria 1 the Venezuelan site, acculturation was significantly correlated with scan only, $\mathrm{r}=.34, \mathrm{p}=.07$. For the Chile site, acculturation was significantly correlated with criteria 1 Sequential Reading, r=.48, and criteria 2 " $\mathrm{Z}$ " pattern, $\mathrm{r}=.45$ (both, $\mathrm{p}<.05$ ).

Table 3. Criteria 1 is displayed for average gaze patterns by location

\begin{tabular}{|c|c|c|c|c|c|c|c|c|c|c|}
\hline Criteria 1 & $\begin{array}{l}\text { Best B } \\
\text { Englis }\end{array}$ & & $\begin{array}{l}\text { Best B } \\
\text { Spani }\end{array}$ & & $\begin{array}{l}\text { Coca } \\
\text { Englis }\end{array}$ & & $\begin{array}{l}\text { Coca } \\
\text { Spani }\end{array}$ & $\begin{array}{l}\text { Cola } \\
\text { h } 1\end{array}$ & $\begin{array}{l}\text { Coca } \\
\text { Spani }\end{array}$ & $\begin{array}{l}\text { Cla } \\
\text { h } 2\end{array}$ \\
\hline & ROC & MIA & ROC & MIA & ROC & MIA & ROC & MIA & ROC & MIA \\
\hline $\begin{array}{l}\text { Sequential } \\
\text { Reading }\end{array}$ & 6.47 & 5.20 & 6.73 & 4.47 & 8.40 & 5.47 & 5.67 & 6.46 & 7.69 & 6.31 \\
\hline Circular Scan & 2.53 & 1.33 & 3.87 & 1.07 & 1.73 & 0.73 & 2.60 & 2.15 & 1.31 & 1.08 \\
\hline $\begin{array}{l}\text { Back and } \\
\text { Forth }\end{array}$ & 1.33 & 0.87 & 1.60 & 1.33 & 1.53 & 2.80 & 1.53 & 0.92 & 1.25 & 0.69 \\
\hline Scan only & 5.40 & 3.40 & 3.20 & 2.73 & 4.33 & 3.13 & 4.47 & 3.38 & 3.06 & 1.92 \\
\hline Title Focus & 1.27 & 1.20 & 1.20 & 1.20 & 1.40 & 2.33 & 1.60 & 2.54 & 1.69 & 1.54 \\
\hline Nav. Reading & 3.07 & 2.67 & 2.47 & 3.27 & 1.60 & 2.20 & 2.20 & 1.92 & 1.56 & 2.69 \\
\hline
\end{tabular}


Table 4. Criteria 2 is displayed for average gaze patterns by location

\begin{tabular}{|c|c|c|c|c|c|c|c|c|c|c|}
\hline \multirow[t]{2}{*}{ Criteria 1} & \multicolumn{2}{|c|}{$\begin{array}{l}\text { Best Buy } \\
\text { English }\end{array}$} & \multicolumn{2}{|c|}{$\begin{array}{l}\text { Best Buy } \\
\text { Spanish }\end{array}$} & \multicolumn{2}{|c|}{$\begin{array}{l}\text { Coca Cola } \\
\text { English }\end{array}$} & \multicolumn{2}{|c|}{$\begin{array}{l}\text { Coca Cola } \\
\text { Spanish } 1\end{array}$} & \multicolumn{2}{|c|}{$\begin{array}{l}\text { Coca Cola } \\
\text { Spanish } 2\end{array}$} \\
\hline & ROC & MIA & ROC & MIA & ROC & MIA & ROC & MIA & ROC & MIA \\
\hline "O" Shape & 2.53 & 1.33 & 3.87 & 1.07 & 1.69 & 0.71 & 1.31 & 1.08 & 2.44 & 2.33 \\
\hline "5" Shape & 0.53 & 0.73 & 1.47 & 0.33 & 1.00 & 0.71 & 1.19 & 0.64 & 0.94 & 1.00 \\
\hline "N" Shape & 1.00 & 0.40 & 1.47 & 0.80 & 0.75 & 0.57 & 0.63 & 0.79 & 0.69 & 0.54 \\
\hline "Z" Shape & 1.73 & 1.87 & 3.00 & 1.67 & 2.69 & 3.07 & 2.50 & 2.43 & 2.94 & 1.77 \\
\hline "X" Shape & 0.67 & 0.73 & 1.27 & 0.87 & 0.50 & 0.57 & 0.63 & 0.57 & 0.56 & 0.85 \\
\hline
\end{tabular}

\section{Discussion}

By using ARSMA-II, correlations between acculturation score and gaze patterns were identified. ARSMA-II is a reliable method to assess the acculturation status of an individual. This provides a consistent measure to compare gaze pattern variance. The two main subscales AOS and MOS should be implemented into future research into cultural divergence.

While the results demonstrate that there was significant variance between Miami and Rochester participants it should not be assumed that culture is the only variable influencing gaze patterns. The directionality and relationship of correlations between websites is not consistent. Ideally, oppositional acculturation scores would show corresponding changes in movement pattern frequency. However those with low ARSMA-II scores seem to remain consistent in gaze behavior.

\subsection{Best Buy}

The versions of the website used are identical except for language which has been modified for "American Spanish". All participants show similar overall patterns on radar charts. Sequential Reading and Circular scan pattern demonstrated positive correlations with acculturation score. Following a cognitive processing explanation is a result of American culture promoting linear processing. While the Circular scan suggests a higher level of familiarity with the language and structure. Acculturation demonstrated a positive correlation with scan only patterns on the Spanish site. This could be an unorganized attempt to find recognizable elements within the site for those with little understanding of the Spanish language. 


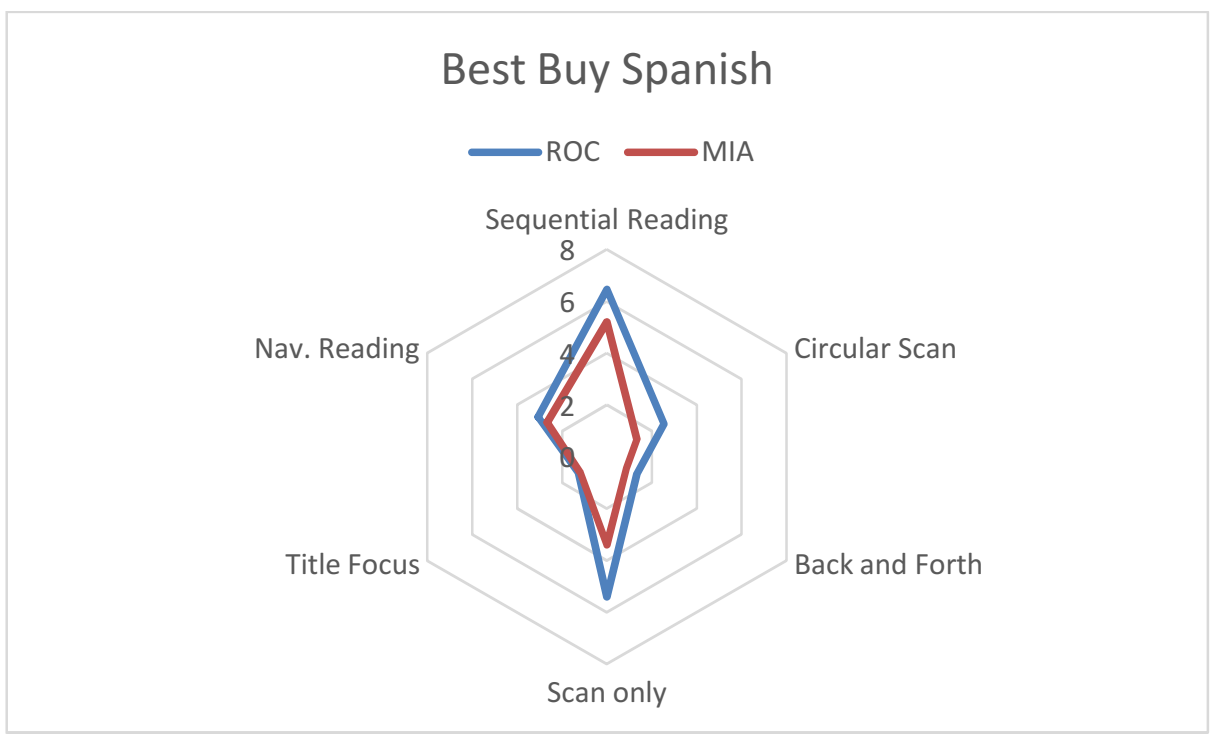

Fig. 4. Criteria 1: Radar Graph of Best Buy Spanish American website. Each axis represents average count of gaze pattern.

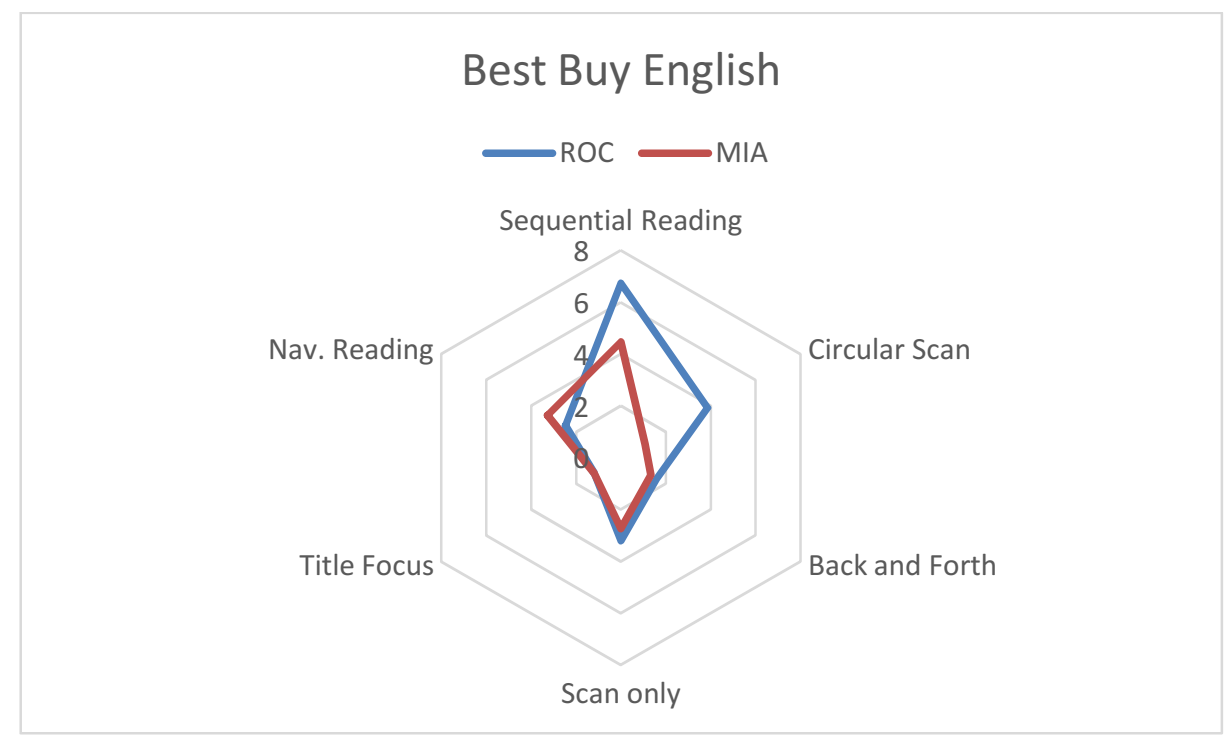

Fig. 5. Criteria 1: Radar Graph of Best Buy English website. Each axis represents average count of gaze pattern. 


\section{$5.2 \quad$ Coca Cola}

The versions of the website have varying structure and information but all color and icons used remain consistent. Since the sites were design for completely different target markets, this means the results can currently only be taken at surface level. While sequential reading demonstrated a consistent positive correlation across the American and Chilean versions of the website, it was not significant in the Venezuela site. Most of the variance in the results may be the result of those unaccustomed with the information attempting to understand the information, resulting in increased sequential reading and linear deconstruction of the site visually.

\subsection{Future Research}

Follow-up research should reuse gaze patterns that showed correlations in this study, while testing new patterns for correlation potential. To add support to these findings, studies should use 2 to 3 websites that isolate changes in design layout: language, color, positioning, image vs. text. In particular, implementation of 2 levels of fixation categories (shallow and deep) may assist in isolating pertinent gaze patterns. It is the hope that future research can extend our understanding of the integral role culture plays in our perception of websites.

\section{References}

1. Ahmed, T., Mouratidis, H., Preston, D.: Website Design and Localisation: A Comparison of Malaysia and Britain. International Journal of Cyber Society and Education, 3-16 (2008)

2. Barber, W., Bardre, A.: Culturability: The Merging of Culture and Usability. Human Factors (1998)

3. Cuellar, I., Arnold, B., Maldonado, R.: Acculturation Rating Scale for Mexican Americans-II: A Revision of the Original ARSMA Scale. Hispanic Journal of Behavioral Sciences, 1-31 (1995)

4. Cyr, D., Trevor-Smith, H.: Localization of Web Design: An Empirical Comparison of German, Japanesem and U.S. Website Characteristics. Journal of the American Society for Information Science and Technology, 1-10 (2004)

5. Dahal, S.: Eyes Don't Lie: Understanding User' First Impressions on Websie Design Using Eye Tracking. Thesis, 1-58 (2011)

6. Deregowski, T.: Perception. In: Triandis, H.C., Lenner, W. (eds.) The Handbook of Cross Cultural Psycology. Allyn and Bacon, Boston (1980)

7. Detweiler, R.: Culture, Category width, and Attributions. Journal of Cross-Cultural Psychology, 259-284 (1978)

8. Dong, Y., Lee, K.-P.: A Cross-Cultural Comparative Study of Users' Perceptions of a Webpage: With a Focus on the Cognitive Styles of Chinese, Koreans and Americans. Special Issue on Cultural Aspects of Interaction Design, 19-20 (2008)

9. Fletcher, R.: The impact of culture on web site content, design, and structure: An international and multicultural perspective. Journal of Communication Management, 259273 (2006) 
10. Hillier, M.: The role of cultural context in multilingual website usability. Electronic Commerce Research and Applications, 2-14 (2003)

11. Hofstede, G.: Culture and Organizations: Software of the Mind. Mc Graw-Hall Book Company, London (1991)

12. Marcus, A., Gould, E.W.: Crosscurrents: Cultural Dimensions and Global Web Interface Design. Interactions, 32-46 (2000)

13. Marino, R., Stuart, G.W., Klimidis, S., Minas, H.: Quantitative measures of acculturation: a review (2011)

14. Nisbett, R.: The Geography of Though: how asians and westerners think differently and why. Free Press, New York (2003)

15. Punchoojit, L., Chintakovid, T.: An Overview of Research on the Accommodation of Culture into Web Design (2012)

16. Segall, M., Campbell, D., Herkovits, M.: Influence of Culture on Visual Perception. Bobbs Merril, Indianapolis (1966)

17. Zahed, F.: A Conceptual Framework for International Web Design. Professional Communication, 83-103 (2001) 